\title{
Study of Tendering Strategy on the Improvement Works of School Building - An Example of Taiwan University Campus
}

\author{
Ling-Er Liou, ${ }^{1,}{ }^{*}$, Ting-Yi Chiang ${ }^{1, b}$ and Yeng-Horng Perng ${ }^{1, c}$ \\ ${ }^{1}$ Department of Architecture, National Taiwan University of Science and Technology, \\ No.43, Sec. 4, Keelung Rd., Da'an Dist., Taipei City 10607, Taiwan (R.O.C.) \\ aD10413002@mail.ntust.edu.tw, ${ }^{\mathrm{b} D} 10313014 @ m a i l . n t u s t . e d u . t w,{ }^{c}$ perng@mail.ntust.edu.tw
}

\begin{abstract}
Keywords: School construction projects, Turnkey method, Taiwan, Engineering management, Improvement measures.

Abstract. This research began with the status of the implementation of school construction projects to explore the relationship between the characteristics of its management and its impact on different levels. Through gathering literature, interviewing experts, statistical methods, and other methods of analysis, ways to improve the tender process were understood. Organizing the domestic and international literature gathered, understanding similar domestic systems, and other cases helped to develop guidelines for the shift of school construction projects into the turnkey method. The selection of appropriate vendors will reduce the likelihood of disputes arising due to compliance issues as well as address project delays and quality issues. This research began by analyzing the causes of the current issues experienced in the universities whose cases were gathered. It was proposed that the proper improvement strategy be the integration of the turnkey method into the construction projects of the schools. It was discovered in the results that using the turnkey method for school construction projects will result in $20 \%$ savings in time and cost. In addition, it was proposed that the establishment of an improved system will facilitate the smooth completion of projects; the turnkey method should be implemented on three major levels including the pre-process, selection of a turnkey vendor, and prudent planning during the implementation stage (compliance management).
\end{abstract}

\section{Introduction}

School construction projects are complicated in Taiwan; traditionally, the tendering processes for contracted work are done separately from design and construction wherein different units handle design and construction. This means that design ideas are often not well communicated, creating a gap between design and construction which affects succeeding projects. Common problems include the long duration of current projects which is further extended, poor budget execution, and the inability for projects to be completed as per expectations. Given the approximately NTD 20 billion budget of universities around the country (close to 10 years of data were collected) [1], insufficient manpower, the inability to control the progress of projects, and the need for current procedures to pass through multiple layers of bureaucracy means that not only is it impossible to resolve issues in the shortest amount of time, but that time and money are unnecessarily wasted. Although engineering technology has advanced in the recent years, the use of resources is still inadequate. Feedback from design and construction experiences cannot be implemented in similar follow-up projects, resulting in functional overlap and resource wastage, directly or indirectly affecting the implementation performance of school construction projects. Only by improving the tendering process can efficiency and quality be improved.

The improvement measure is to hand over the design and construction to the private sectors for their coordination and construction. In other countries such as the United States, England, Japan, and Singapore, a different tendering strategy called Design-Build [2, 3] was proposed to address the current issues. Article 24 of the Government Procurement Act contains a precise definition of this strategy [4]. Although the turnkey method has been used for many years, its application in school construction projects is rare. Will the turnkey method be beneficial to school construction projects? How should turnkey vendors be selected? What are the mechanisms for its application? There is no single tailor-made process to be followed for school construction projects which has resulted in 
authorities not knowing what type or scale of projects will be able to benefit most from this approach nor is it known how to implement these processes even though they are interested in it. These are the issues that this research seeks to address.

\section{Methodology}

This research will explore the use of the turnkey method on school construction projects through gathering literature, expert interviews, statistical methods, brainstorming by experts, and other related methods. Below is a summary of these methods:

Literature analysis: Based on a certain research purpose or topic, this is the gathering of information, investigative report, industry news, and other forms of literature. It is a method to completely and accurately get a grasp on the research question wherein all the gathered information will be organized after being analyzed.

In-depth interviews: This is to get a deep and solid understanding of what the interviewees know about the topic which is why depth is more important than breadth $[5,6]$.

Case analysis: Harvard University developed this in 1880. This method seeks to take the problems experienced in the actual case as the focus of the study, and then delve into its analysis. By determining the possible causes of the problems present in the case, ways to solve or address the problems are proposed.

Accordingly, the cases of similar domestic systems and others will be understood, the benefits of using the turnkey method for school construction projects will be explored, and a set of the most appropriate guidelines for the schools' use of the turnkey method will be proposed. The related literature shows that using the Design-Build method can reduce the instances of contracting and the time and money spent [7]. Of course, the turnkey method not only combines design with construction but can also create a single unified organization through teamwork, helping to reduce transaction costs. At the same time, an author once published in the journal of the American Society of Civil Engineers (ASCE) that the tendering process for construction projects is more suited to a system that combines design with construction [8-11]. Therefore, the application of the turnkey method to school construction projects will be beneficial.

\section{Status and Problems}

Schools, design units, and construction vendors are already accustomed to the traditional methods of operation, but this has caused many problems such as the large amount time required to proceed from design to construction, difficulties in separating the scope of water and electrical works from civil works, and the heavy workload from contract management, frequency of tendering, contract amendments, managing complex processes, repetitive work, manpower and resources, and the time and costs spent on design and construction projects. These not only waste money and resources but are also ineffective in the usage of such. The delays and inefficiencies of completed school works were explored. Key elements which the school handled such as operating time cost, design changes, interface integration management were investigated and analyzed.

\section{Operating Time Cost}

This research gathered the cases of 19 schools and discovered that the time and money spent during the design and construction phases are high due to factors such as tendering failure, re-application of tenders, and design changes (as shown in Table 1). On average, design and construction (including time spent on the selection of firms) generally take 6 to 7 years, generating additional costs and increasing the workload due to tender awarding, contract management, and interface integration management. This generates a relative increase in expenses incurred from searching for vendors and contracting. 


\section{Design Changes}

Non-construction professionals mostly staff the unit responsible for the school construction projects. Past cases have shown that if the design unit does not create a comprehensive design, the construction that follows is not able to properly function, making design changes necessary. Every change to the design requires significant amounts of time, resources, and manpower. The amount of time and money spent are important factors that affect the progress and quality of the works. By combining design and construction through contract management, the turnkey method can involve key things to be considered during construction into the design process, reducing the number of changes to the design, time spent on bureaucratic procedures, and management costs. Statistical analysis of previous cases and interviews of experts have shown that applying design changes in projects valued below NTD 100 million takes, on average, around 4 to 8 months. For projects valued above NTD 100 million, the time spent is approximately more than one year [4] (please refer to Table $1)$.

Table 1. For the list of school construction projects

\begin{tabular}{|c|c|c|c|c|c|c|c|}
\hline Frequency & $\begin{array}{l}\text { Project } \\
\text { name }\end{array}$ & $\begin{array}{l}\text { Tender } \\
\text { winner }\end{array}$ & $\begin{array}{c}\text { Expected } \\
\text { completion }\end{array}$ & $\begin{array}{c}\text { Actual } \\
\text { completion }\end{array}$ & $\begin{array}{c}\text { Original } \\
\text { scheduled } \\
\text { duration }\end{array}$ & $\begin{array}{c}\text { Differences in } \\
\text { number of days } \\
\text { (Actual increase } \\
\text { in duration) }\end{array}$ & $\begin{array}{c}\text { Bid price } \\
\text { (NTD } 100 \\
\text { million) }\end{array}$ \\
\hline 1 & A & $2010 / 12 / 22$ & $2013 / 03 / 31$ & $2014 / 08 / 03$ & 830 & 490 & 3.88 \\
\hline 2 & B & $2008 / 12 / 18$ & $2011 / 08 / 10$ & $2012 / 09 / 30$ & 965 & 417 & 23.1 \\
\hline 3 & $\mathrm{C}$ & $2010 / 05 / 10$ & $2011 / 08 / 05$ & $2014 / 05 / 01$ & 452 & 1000 & 1.94 \\
\hline 4 & $\mathrm{D}$ & $2009 / 12 / 22$ & $2012 / 05 / 08$ & 2013/08/08 & 868 & 457 & 11.46 \\
\hline 5 & $\mathrm{E}$ & $2010 / 05 / 14$ & $2012 / 12 / 07$ & $2013 / 12 / 04$ & 938 & 362 & 1.96 \\
\hline 6 & $\mathrm{~F}$ & $2003 / 10 / 28$ & $2005 / 12 / 31$ & $2007 / 07 / 11$ & 795 & 557 & 2.45 \\
\hline 7 & G & $2010 / 07 / 05$ & $2012 / 01 / 15$ & $2013 / 06 / 07$ & 559 & 509 & 5.52 \\
\hline 8 & $\mathrm{H}$ & $2010 / 07 / 14$ & $2013 / 03 / 31$ & $2015 / 06 / 22$ & 991 & 813 & 8.86 \\
\hline 9 & I & $2010 / 06 / 15$ & $2012 / 11 / 13$ & 2015/07/06 & 882 & 965 & 2.01 \\
\hline 10 & $\mathrm{~J}$ & $2008 / 10 / 29$ & $2010 / 09 / 07$ & $2012 / 12 / 02$ & 678 & 817 & 2.26 \\
\hline 11 & $\mathrm{~K}$ & $2004 / 11 / 30$ & $2005 / 12 / 30$ & $2007 / 07 / 17$ & 395 & 564 & 2.95 \\
\hline 12 & $\mathrm{~L}$ & $2009 / 10 / 13$ & $2010 / 10 / 31$ & 2011/10/11 & 383 & 345 & 2.14 \\
\hline 13 & M & $2010 / 02 / 25$ & $2011 / 06 / 20$ & $2012 / 06 / 25$ & 480 & 371 & 3.21 \\
\hline 14 & $\mathrm{~N}$ & $2010 / 12 / 30$ & $2012 / 06 / 30$ & $2014 / 01 / 28$ & 548 & 577 & 7.77 \\
\hline 15 & $\mathrm{O}$ & $2009 / 06 / 16$ & $2011 / 11 / 10$ & 2013/12/06 & 877 & 757 & 6.49 \\
\hline 16 & $\mathrm{P}$ & $2011 / 02 / 10$ & $2012 / 10 / 11$ & $2013 / 12 / 20$ & 609 & 435 & 8.58 \\
\hline 17 & Q & $2012 / 10 / 15$ & $2014 / 03 / 18$ & $2015 / 10 / 15$ & 519 & 576 & 4.53 \\
\hline 18 & $\mathrm{R}$ & $2010 / 12 / 14$ & 2013/01/19 & $2014 / 01 / 08$ & 767 & 354 & 4.22 \\
\hline 19 & S & $2006 / 02 / 15$ & $2008 / 01 / 10$ & $2009 / 09 / 17$ & 694 & 616 & 4.26 \\
\hline
\end{tabular}

Note:

I Assuming that the original duration of construction is set at 830 days, the cost is at NTD 388 million, and there was an extension of 490 days until actual completion, the additional cost incurred is $(388 / 830) * 490=$ NTD 229 million. As such, cost of time and money incurred using the traditional method is quite large.

I It takes around two years from the completion of the design phase to successful contracting to vendors for construction. 


\section{Interface Integration Management Operations}

If each construction project is not able to be successfully tendered, it means that the number of contracting operations will increase and the amount of work to be done by the school for contract management will likewise increase. Based on the current operating methods, there is a definite need to increase workforce and workload. Cases wherein design and construction are separately conducted have shown that interfacing will comparatively increase which results in engineering disputes or delays. Given that interfacing frequently causes these, it is only through the combination of design and construction being managed as a single contract that can solve these problems. By having the turnkey vendor take responsibility for coordinating the design and construction, the amount of interfacing can be reduced, reducing the likelihood of work disputes from arising, thus speeding up overall completion. Through statistical analysis, using the volume of time spent on organizing the awarding of tenders, each tender awarding process takes up 3 to 6 months of administrative work.

\section{Exploration of applicability on school construction projects}

After reviewing current operations (detailed in Table 1), it was discovered that the amount of time spent on design and construction is long, the amount of work for the tendering process is too much, and that there are too many instances of design changes. The appropriateness of the operating method plays an important role. Issues such as the operating procedures for the entire plan, future interfacing, and coordination and integration not only affects the progress of works but moreover, has an inseparable link between quality and costs.

First, based on the cases gathered, the number of school construction projects that used the turnkey method are few. It was discovered that the main reasons for this are the doubt that schools have towards selecting a good turnkey vendor, unfamiliarity with the turnkey method, and other such reasons. Secondly, in other projects that used the turnkey method, their implementation effectiveness, responses to the turnkey method which included fostering a principle of mutual trust, giving vendors autonomy, organizers providing quality work environment and completion of required tasks, elimination of uncertainties regarding time cost, reducing monetary risks for vendors $[12,13]$, and other recommendations are all available for reference for this research.

Lastly, it was made known through the interviews with experts and organizing directors that compared to other procurement methods, the combination of design with construction helps to enhance project value and reduce disputes $[14,15]$. Therefore, this research proposes that it be considered to have the design and construction be coordinated and implemented by the private sector to improve efficiency and construction productivity by having it all handled by a single vendor. This does not involve future operations which is why it is highly feasible. Design-Build is clearly different from current operating methods; the turnkey method can help shorten implementation time, reduce interface integration operations, improve engineering expertise, and reduce construction management costs.

\section{Supporting measures for the use of the turnkey method on school construction projects}

It is known from Table 1 that from the data of the cases gathered, the results have shown that the average time spent on design and construction (including time spent choosing vendors) is around 6 to 7 months; this results in additional costs for the school. The key success factor affecting the use of the turnkey method on school construction projects is the need to have proper system planning [10, 14, 16]. After organizing the interviews conducted with experts and organizing directors, the following items should be noted when the school has decided to use the turnkey method:

\section{Pre-process:}

The job details, obligations, and other particulars of the turnkey method are described in detail below.

I Risk sharing: The vendor shall conduct a detailed investigation of the building, and the delay caused by some uncertain factors shall be reasonably shared when the contract is made. 
I Reasonable time estimate: This should be provided to avoid short lead time for the vendor leading to them not understanding the project and finally resulting in financial issues, unscrupulous vendors cutting corners which reduces quality or generates delays, or other such problems.

I Schedule and condition of payments: This, as well the timing of design and construction reviews by the school, should be clearly stated in the contract.

I Design and construction requirements of the program: This includes the construction group, sequence, planning and management. Also, it can be determined based on the construction plan whether there will be a conflict with the design.

I Design and construction by the turnkey vendor: The ability and experience of the vendor is a key success factor which is why the selection of a vendor with experience, technical abilities, and financial abilities is an important task.

\section{Tendering Method:}

A three-stage qualification tendering process based on qualification, technical ability, and price and be used. Depending on the type of project, the notice of tender can require a single tender or multiple-step opening of tenders. After first passing the qualification bidding stage, the technical and pricing bids are submitted. The use of the multiple-step opening of tenders is the most appropriate tendering method for the school and vendors.

\section{Implementation Method}

The school first completes the requirement specifications then the turnkey vendor will be responsible for the design and construction works; this is to generate the efficiency benefits.

\section{Selection Stage}

How should the best turnkey vendor be chosen through the selection system? To ensure that the turnkey vendor will be able to meet the needs of the client, $80 \%$ of survey respondents believe that the following are key factors that should be accounted for:

I Qualifications: Financial situation, educational experience and abilities, related achievements and certifications, and the past project experience and performance of the turnkey vendor.

I Design capability: Overall creativity in architectural design, comprehensiveness of space planning, suitability of equipment planning, and appropriateness of materials used.

I Project execution capability: Construction feasibility and safety, the main issues and countermeasures, construction plans, project organization and division of responsibilities, quality management plan, schedule and budget allocation plans and content [17].

\section{Implementation stage (compliance management)}

There must be an assessment system for the turnkey method. During the compliance management stage, things that should be noted include budget control, progress control, quality control, and safety management. Milestones should be established for each stage of the project lifecycle. At the same time, while the turnkey vendor is responsible for the coordination of design and construction, the school should set the schedule and standards for quality audits of the design management operations and design quality of the vendor. Lastly, the project controller and manager of the school should specify the construction plans, quality plans, labor safety programs, and other relevant documents that the vendor should provide during the implementation stage. This way, the school will have access to details on changes in design, prices, testing, and customer acceptance, to ensure the quality of the turnkey project.

Based on the problems currently faced by the schools, this research has proposed solutions and best practices to improve the turnkey method. At the same time, it was made known through the interviews with experts and organizing directors that this can indeed reduce the amount of time and money spent by the school on the projects by $20 \%$.

\section{Conclusion and Recommendations}

Through interviews with experts and statistical analysis, the research findings confirmed that using the turnkey method can indeed help the school reduce the amount of time and money spent on projects by $20 \% .80 \%$ of experts interviewed believe that the use of the turnkey method on school construction projects is beneficial. At the same time, it was systematically discovered that the shift to 
the turnkey method could save two years' time and NTD 200 million compared to estimates. Therefore, to achieve the expected functions and goals of school construction projects in using the turnkey method, in particular, qualified vendors should be selected, contracts should clearly specify design and construction standards, design audits and construction supervision and management and other such systems should be in place. It is recommended that follow-up studies develop a comprehensive operation plan and process flow for the turnkey method which will reduce the cost of searching for vendors and the cost of learning this method. This serves as a reference for schools.

\section{References}

[1] Information on https://www.edu.tw/

[2] DBIA, Design-Build Contracting Guide, Design-Build Institute of America, 2000.

[3] FIDIC, Conditions of Contract for Plant and Design-Build, The Federation Internationale Des Ingenieurs Conseils. First Edition, 1999.

[4] Information on https://www.pcc.gov.tw/pccap2

[5] H. J. Rubin, I. S. Rubin, Qualitative interviewing: The art of hearing data. Thousand Oaks, CA: Sage, 2011.

[6] R. S. Weiss, Learning from strangers: The art and method of qualitative interview studies. Simon and Schuster, 1994.

[7] S. D. Anderson, \& R. L. Tucker, Improving project management of design, Journal of Management in Engineering. 10(4) (1994) 35-44.

[8] Information on http://www.asce.org/

[9] C. M. Gordon, Choosing appropriate construction contracting method, Journal of construction engineering and management. 120(1) (1994) 196-210.

[10]D. K. H. Chua, Y. C. Kog, \& P. K. Loh, Critical success factors for different project objectives, Journal of construction engineering and management. 125(3) (1999) 142-150.

[11]N. Carpenter, \& D. C. Bausman, Project delivery method performance for public school construction: Design-bid-build versus CM at risk, Journal of Construction Engineering and Management. 142(10) (2016) 05016009.

[12]L. A. Ellingson, What Should We Teach about Design-build Contracts? A Learning Module, Journal of Construction. 7(3) (2002) 117-136.

[13]K. R. Molenaar, \& A. D. Songer, Model for public sector design-build project selection, Journal of Construction Engineering and Management. 124(6) (1998) 467-479.

[14]E. W. Lam, A. P. Chan, \& D. W. Chan, Determinants of successful design-build projects, Journal of Construction Engineering and management. 134(5) (2008) 333-341.

[15]K. Adeyeye, Teaching construction contracts: mutual learning experience, Journal of Legal Affairs and Dispute Resolution in Engineering and Construction. 1(2) (2009) 97-104.

[16]J. Liu, Q. Xie, B. Xia, \& A. J. Bridge, Impact of design risk on the performance of design-build projects, Journal of Construction Engineering and Management. 143(6) (2017) 04017010.

[17]A. D. Songer, \& K. R. Molenaar, Project characteristics for successful public-sector design-build, Journal of construction engineering and management. 123(1) (1997) 34-40. 